\title{
CAISSON BREAKWATER DESIGN FOR SLIDING
}

\author{
Steven Hutchinson ${ }^{1}$, Martin Young ${ }^{2}$, and Alasdair Macleod ${ }^{3}$
}

\begin{abstract}
The offshore caisson breakwater at Costa Azul installed in 25m water depth is designed to withstand Pacific swell waves up to a PLS test case Hs $9.2 \mathrm{~m} \mathrm{Tp} 18.6 \mathrm{~s}$. Overall stability design is in accordance with the recommendations of PIANC WG 28. The critical failure mechanism is sliding, and the caisson base is cast with a deliberately roughened (serrated) profile to increase sliding resistance and optimize the caisson cross section. Site based testing at prototype scale was conducted to validate the coefficient of friction used for design between the caisson base and nominal $100 \mathrm{~mm}$ single size granular bedding material. This testing confirms that the use of a suitably dimensioned serrated base profile allows the full internal angle of friction (with allowance for dilation) of the bedding material to develop at the base of the caisson, allowing the cross section design to be optimized.
\end{abstract}

Keywords: Design \& Performance Analysis; Coefficient of Friction Caisson Breakwater; Sliding Stability PIANC WG28. Validation Testing

\section{INTRODUCTION}

The recommendations of PIANC Working Group 28 represent the state of the art for the design of breakwaters with vertical and inclined concrete walls. Yet in the report of Sub-Group C, it is noted that:

"Although the concepts of friction are classical and have been studied for so long, there is a surprising divergence in the figures used in design, and lack of agreed experimental data.”

This paper describes the physical testing carried out at prototype scale to validate the coefficient of friction for sliding used in the overall stability design for the offshore caisson breakwater at Costa Azul. The detailed design for the caissons uses a serrated profile over the soffit of the base slab, following the approach given in BS 6349 and EAU 90 to increase the coefficient of interface friction so as to equal the internal angle of friction of the granular bedding layer.

\section{Offshore Caisson Breakwater}

Energía Costa Azul is an LNG receipt terminal on the Pacific coast of Baja California, approximately $90 \mathrm{~km}$ south of San Diego [Figure 1]. The single LNG tanker berth is situated on a rock promontory, with deep water access and is sheltered by a detached offshore breakwater.

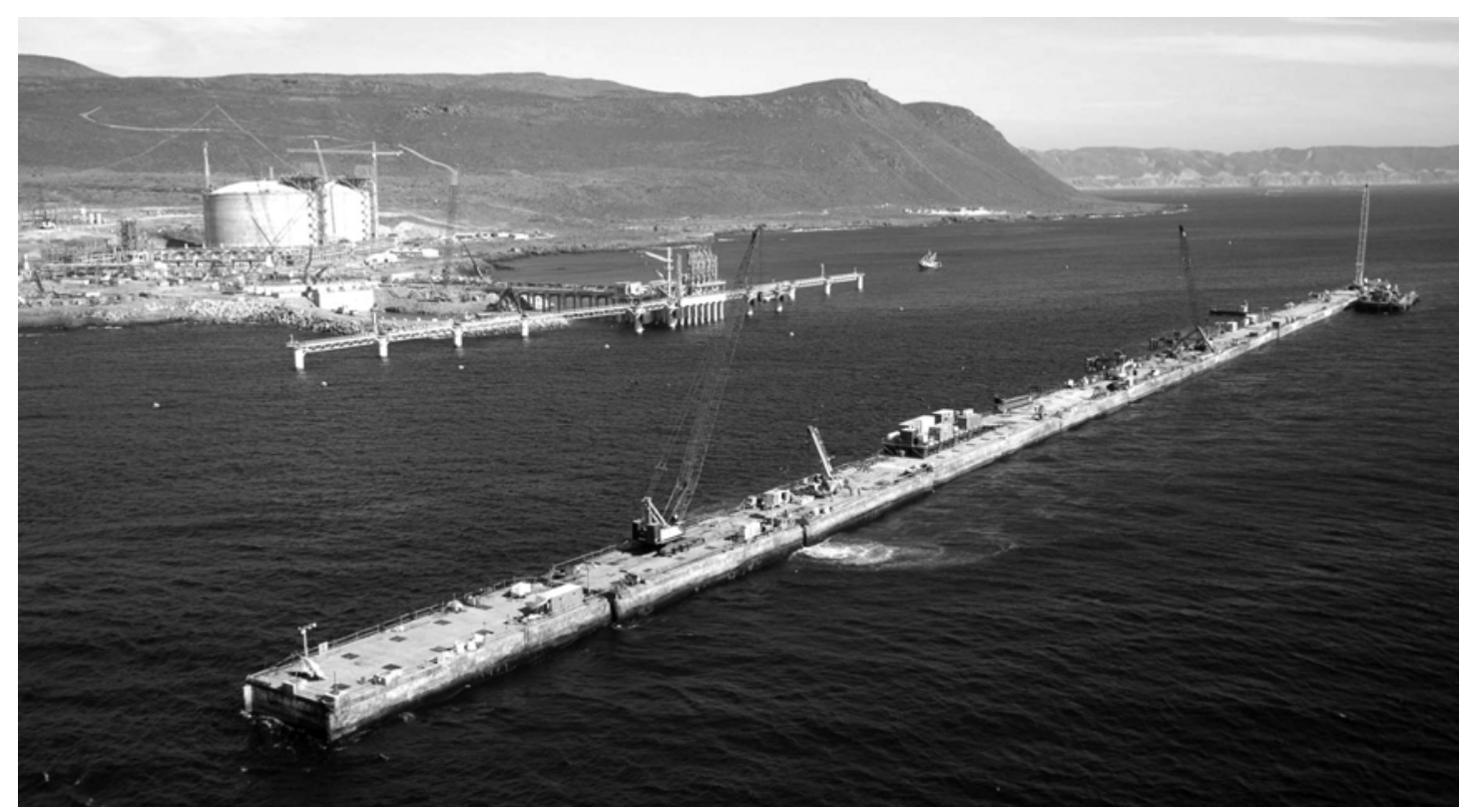

Figure 1 Breakwater (length 650m) after installation of 12th caisson

\footnotetext{
${ }^{1}$ HR Wallingford, UK. s.hutchinson@hrwallingford.co.uk

${ }^{2}$ Scott Wilson Ltd., UK. martin.young@scottwilson.com

${ }^{3}$ Costain Ltd., UK. alasdair.macleod@costain.com
} 
The breakwater is located some 200m offshore to provide sufficient navigable width in front of the berth, and to limit operating wave height at the berth to acceptable limits. The breakwater structure is designed to withstand extreme Pacific storm events. In order to minimise rock demand and impact on the marine environment - which includes the migratory route for the Pacific Grey whales - the Owner's Engineer specified a caisson structure for the breakwater to minimise the breakwater footprint on the seabed, and the design considers removal of the structure at the end of its 25 year design life.

During design wave conditions at the terminal, LNG tankers will leave the berth, and wave overtopping is not a constraint for the breakwater design. This allows the breakwater to be relatively low crested - to reduce incident wave load, and to optimise construction cost.

The offshore breakwater at the Energía Costa Azul LNG terminal in Baja California, Mexico comprises 12 reinforced concrete caissons, with a total length of $650 \mathrm{~m}$, installed in $25 \mathrm{~m}$ water depth on a low rubble mound foundation pad from November 2006 to October 2007.

\section{Design Wave Climate}

Extreme value analysis of hindcast wave data from recorded extratropical cyclones and synthetic hurricane modeling were used by the Owner to determine design wave conditions for the caisson breakwater [Table 1].

\begin{tabular}{|l|l|l|l|}
\hline Table 1. Design Wave Climate (Central Estimate) \\
\hline Design Limit State & Return Period & Hs & Tp \\
\hline Ultimate Limit State (ULS) & 25 year & $6.3 \mathrm{~m}$ & $15.4 \mathrm{~s}$ \\
Progressive Collapse Limit State & 1,000 year & $9.2 \mathrm{~m}$ & $18.6 \mathrm{~s}$ \\
(PLS) - unfactored test case & & & \\
\hline
\end{tabular}

\section{Caisson Characteristics}

Two sizes of caissons were produced - both with the same cross section. The caisson dimensions are based on multiples of a standard cell size - simplifying slipform assembly and operation [Table 2].

\begin{tabular}{|l|l|l|}
\hline \multicolumn{2}{|l|}{ Table 2. Caisson Characteristics } \\
\hline Caisson Type & 6 Cell Caisson & 9 Cell Caisson \\
\hline Length & $46.3 \mathrm{~m}$ & $68.7 \mathrm{~m}$ \\
Cast RC Volume & $6,700 \mathrm{~m} 3$ & $10,100 \mathrm{~m} 3$ \\
Reinforcement & $1,980 \mathrm{t}$ & $2,800 \mathrm{t}$ \\
Even Keel Displacement & $21,450 \mathrm{t}$ & $31,700 \mathrm{t}$ \\
\hline
\end{tabular}

\section{Caisson Production}

When compared to an equivalent rubble mound structure, use of caissons can produce rapid progress results on site for the permanent works. However, off-site production of caissons demands extensive facilities and resources.

A purpose designed casting basin, lock gate, fit-out jetty, load out quay and project harbour were constructed $26 \mathrm{~km}$ south of the breakwater site in the port of Ensenada for caisson production. The twelve caissons were produced over an eighteen month period from April 2006 to September 2007.

\section{CROSS SECTION DESIGN}

Traditionally a caisson is rectangular in cross section, however in deep water the construction cost of carrying the full caisson section above water level becomes significant. The alternative is to stop part of the cross section at a lower level, and to design the reduced section as a vertical cantilever above a wider base. Generally a wider base is required to limit the applied bearing pressures on the foundation, and generate sufficient base friction against sliding.

The FEED study recognised this cost optimisation, and included a wide shoulder section stopped below water level and a narrower turret rising to the design crest level. This turret was positioned centrally along the caisson, forming an inverted " $T$ " shape. During the detailed design stage the turret was moved to the seaward edge of the caisson, making an "L" shape [Figure 2]. This change had the following overall design benefits:

- Increased stability against overturning due to more effective installed weight distribution.

- Improved caisson floating stability during inclined installation.

- Reduced risk of breaking waves on turret (no seaward shoulder). 




Figure 2 Cross Section Breakwater Trunk - showing "L" Shape Caisson

\section{Serrated Base Profile}

With the turret positioned seaward, stability against overturning due to incident wave loading is not the critical failure mode, and the width of the cross section was governed by generation of sufficient base friction against sliding.

A pressed steel shutter [Figure 3] was used to form the serrations on the soffit of the caisson base slab. During float up of the caissons the continuous voids between the serrations and the casting bed meant that hydrostatic pressures were immediately balanced and avoided the potential problem of suction and sudden release of the caisson from the casting bed.

Each of the serrations is a $300 \times 100 \mathrm{~mm}$ unequal angle section, giving an effective serration depth of $90 \mathrm{~mm}$ and a leading face angle of approximately $70^{\circ}$ to the vertical.



Figure 3 Casting bed for serrated caisson base slab

\section{Granular Bedding Layer}

The caissons are installed on a 500mm thick granular bedding layer over the prepared foundation. Finished tolerance on this bedding layer is tight $(+/-100 \mathrm{~mm})$ to ensure good distributed contact with the caisson after installation.

Nominal $100 \mathrm{~mm}$ single sized granular material can be screeded to level with relative ease underwater by diver, and is used for the bedding layer under the caisson. The produced quarried material for the bedding layer is a crushed angular rough cobble sized stone with average compressive 
strength $330 \mathrm{MPa}$ estimated from point load index tests. Its petrographic description is a combination of Bassalt, Granite and Gabro.

\section{CONCEPT DESIGN ASSUMPTIONS}

The design was prepared in accordance with the recommendations of PIANC Working Group 28, with particular reference to the guidance given in BS 6349 for the development of sliding resistance of the caissons over the prepared bedding layer.

\section{PIANC Working Group 28}

Base friction against sliding is reported in detail by Subgroup C [Table 3]. They note that there is a surprising difference between national codes of practice for design values of coefficient of friction and corresponding factor of safety.

\begin{tabular}{|l|l|l|}
\hline \multicolumn{2}{|l|}{ Table 3. Coefficient of Friction - Precast concrete against rubble } \\
\hline National Code & Coefficient of Friction \\
\cline { 2 - 3 } & Smooth & Serrated \\
\hline Japan (Technical Standards for Port & 0.6 & \\
and Harbour Facilities) & 0.7 & \\
Spain (ROM 0.5-94) & $\delta=2 / 3 \phi_{r}$ & $\delta=\phi_{r}$ \\
UK (BS 6349 Pt. 2 - 1988) & $\delta=2 / 3 \phi_{r}$ & $\delta=\phi_{r}$ \\
Germany (EAU 90) & $\tan \phi^{\prime}$ (often 0.58) & \\
France (Fascicule No. 62, titre V) & \\
\hline
\end{tabular}

Both the Japanese and French have carried out model tests to examine coefficient of friction. The test methods used consisted of applying a horizontal force to a block of concrete placed on a gravel or stone bed, and recording both applied force and displacement [Figure 4].
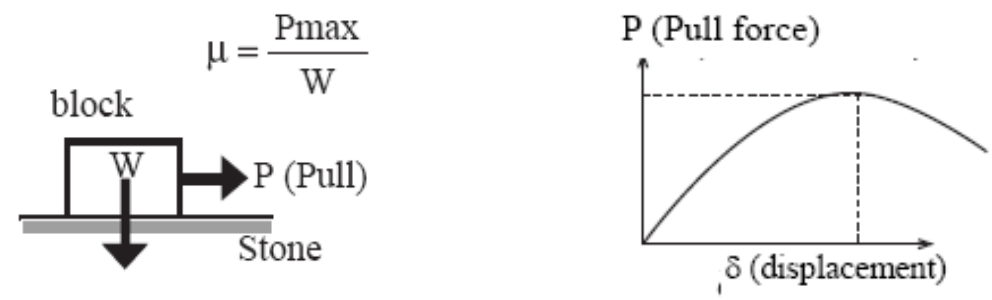

Figure 4 PIANC WG 28 Friction Concepts

The coefficient of friction is determined from the yield point, where the applied force is sufficient to overcome friction and cause the block to slide. It is noted that the coefficient of friction is low at initial construction, but increases in time after compaction by storms and self-weight consolidation.

\section{BS 6349}

Section 5.4.2 of BS6349-7: 1991 in discussing the coefficients of friction on the underside of a caisson, states that "Floating caissons are generally constructed with a flat base to rest on a prepared level bed ... The bases of caissons are sometimes cast on corrugated formwork to give a rough underside to the base in order to increase the resistance to sliding (see 5.3.1.4 of BS 6349-2:1988)."

BS 6349-2:1988 Section 5.3.1.4, states "The depth of the serrations should be comparable to the average stone size of the rubble bed; an angle of friction $\delta=\phi_{r}$ may then be assumed instead of $\delta=2 / 3 \phi_{r}$ " where:

$\delta=$ Angle of friction between base and bedding layer

$\phi_{r}=$ Internal angle of friction within bedding layer

\section{Internal Angle of Friction}

Angle of friction for gravels is commonly taken between $35^{\circ}$ and $45^{\circ}$ depending on packing density. The Rock Manual (CIRIA SP83/CUR 154) provides guidance on assessment of angle of friction based on packing, particle roughness, shape, size, and an equivalent strength. The design assumed an angle of friction for the nominal $100 \mathrm{~mm}$ cobble sized granular bedding layer of $45^{\circ}$. 
PIANC WG28 requires that the analysis of rupture surfaces is carried out using a reduced effective value for the internal angle of friction $\left(\phi_{d}\right)$ to take account of dilation, following the relationship given in Hansen (1979):

$$
\tan \phi_{d}=\frac{\sin \phi^{\prime} \cdot \cos \psi}{1-\sin \phi^{\prime} \cdot \sin \psi} \text { where } \psi \text { is the angle of dilation }
$$

Whilst a literature search reveals data for the dilatancy of sands, there is an absence of test results for engineered rockfill such as the bedding material used under the caissons. An empirical relationship $\psi=\phi-30^{\circ}$ has been suggested for coarse granular materials, however the uncertainty on the values for $\phi_{d}$ and $\psi$ justified taking an alternative direct approach to measure friction.

The design assumes a reduced angle of friction between the serrated concrete base of caisson and bedding layer of 38 degrees, giving an expected coefficient of friction of 0.78 .

\section{VALIDATION TESTING}

Even though the design approach given in BS 6349 is unambiguous, the cross section design of the caisson breakwater design for Costa Azul, and in particular the width of the caissons, is highly sensitive to the selected value for coefficient of friction for sliding. Site based validation testing was conducted to confirm the coefficient of friction for sliding between the caisson base and the bedding layer.

\section{Type of Test}

A simple shear test, along the lines of the testing reported in PIANC WG28 was planned. This is straightforward in the laboratory, but becomes more complicated when the material being tested is cobble sized. As far as was practicable, a test procedure was developed to replicate actual conditions under the caissons. A test block with prototype scale serrations was placed on a prepared area of bedding layer and loaded in shear with a hydraulic jack from a designed reaction block until yield was observed [Figure 5].

Recognition was given from the outset to the inherent variability in the preparation (density) of the granular bedding material, and in the placement of the test block - and therefore the test programme included repeat testing so that a statistically reliable result could be derived.

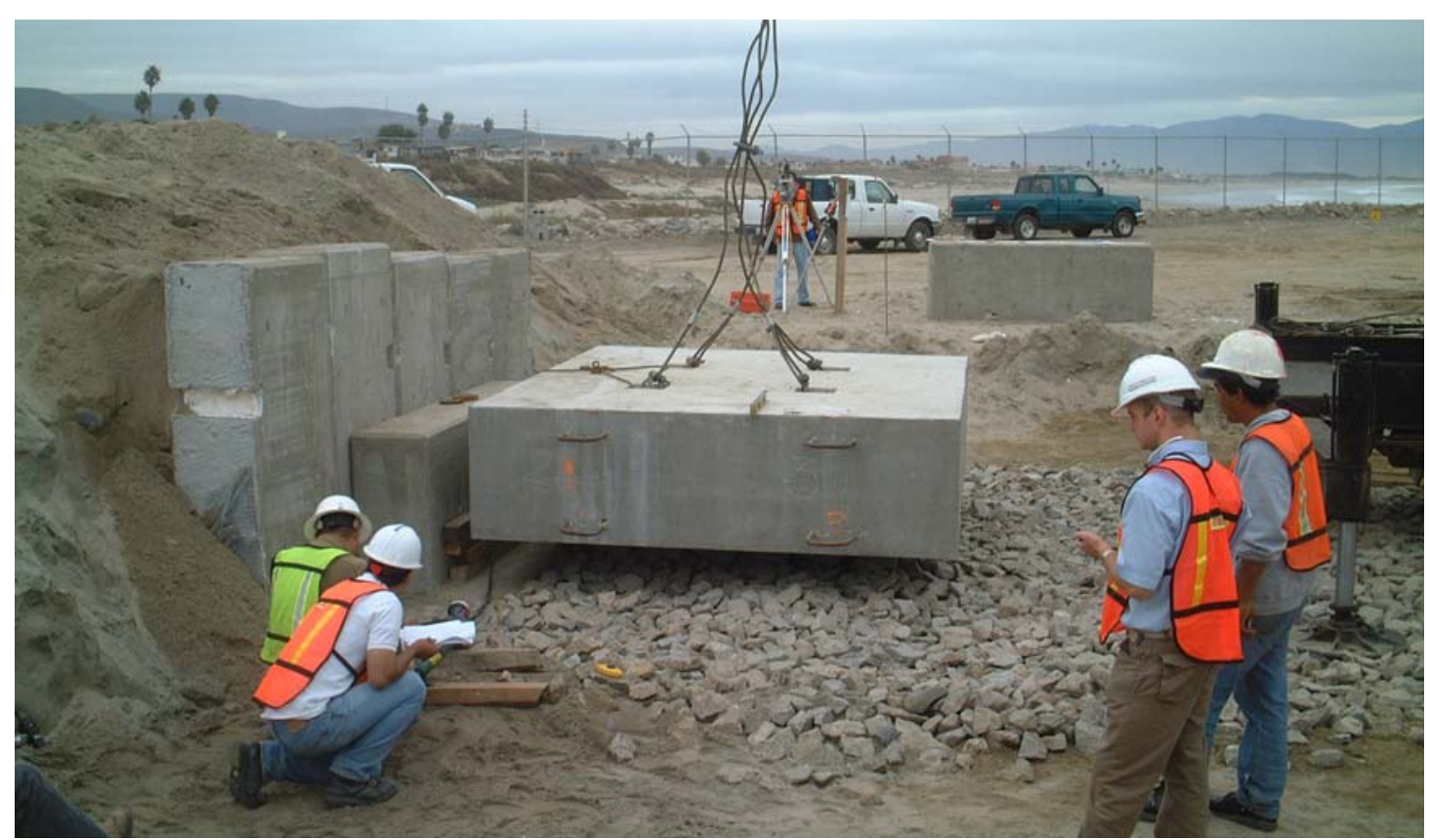

Figure 5 "Push Test" at $75 \mathrm{KPa}$ average bearing pressure in progress 
ULS Wave Loading Conditions

Limiting friction occurs at the point that the caisson starts to slide. This is a ULS condition (yield), and friction testing therefore reproduces the vertical effective stress occurring with the ULS wave loading on the caisson.

Wave loading under the wave crest is the predominant loading condition. Under the wave trough there is a seaward pressure that can cause reverse sliding. Calculation demonstrated that even when assuming a flat profile over the base slab, meaning that only 2/3 of the internal angle of friction of the bedding layer is assumed, seaward sliding was not critical. Testing was only conducted for landward sliding under the wave crest loading.

\section{Concrete Test Block}

It was impractical to make a test block the full caisson width at prototype scale. The length of the test block was made sufficient to minimise boundary effects and included six serrations with an overall plan contact area $1.9 \mathrm{~m}$ long by $1.1 \mathrm{~m}$ wide.

Bearing pressure on the caisson base varies across its width due to the lever arm of the resultant wave pressure acting on it. Testing with the shortened test block therefore examined friction generated at the maximum and minimum effective bearing pressures $(195 \mathrm{kPa}$ and $75 \mathrm{kPa})$ under the caisson associated with the ULS wave crest loading. The single piece test block was designed to generate the minimum bearing pressure, and was detailed so that kentledge could be added to the top to increase this to the maximum bearing pressure.

\section{Bedding Layer Surface Preparation}

The bedding layer under the caissons is $0.5 \mathrm{~m}$ thick, overlying a shallow quarry run rock mound, and sliding at the interface between caisson base slab and the bedding layer is the critical failure surface. During initial grounding of the caissons on the bedding layer an amount of redistribution and leveling is expected as the caisson beds in. For the test, the bedding layer was placed to the same thickness in a loose condition over a compacted foundation, and hand screeded to level to similar tolerance $(+/-100 \mathrm{~mm})$ as might be achieved by a diver underwater. The test bed was excavated and reconstructed before each test.

\section{Applied Loading}

Applied horizontal load was measured by calibrated digital pressure gauge on the hydraulic jack. The horizontal displacement occurring during the test exceeded the stroke length of the hydraulic jack and therefore the full test load was developed incrementally as follows:

- loading the test block until the horizontal deflection was equal to the stroke length of the jack.

- $\quad$ releasing the load, whilst recording the elastic recovery.

- $\quad$ resetting the jack with the ram collapsed and reloading.

When the jack was reset, packing was placed between the jack and reaction block so that jack was square against the test block and the horizontal test load was always parallel with the shear plane. The above procedure had the considerable benefit of demonstrating the response under quasi-cyclic loading conditions. The calculated mass of the concrete test block and kentledge was checked across a weigh bridge. Actual weight was used in the analysis.

\section{Displacement}

A millimetre rule was set horizontal and glued to the side of the test block. This was read remotely by theodolite to measure horizontal displacement. As the datum was remote from the test and the reaction block, the measurement required no correction for displacement of the reaction block as it took up load from the hydraulic jack.

Levels were taken at the front and back of the test block, relative to a local datum. These measurements determine the slope on top of the bedding stone layer, relative to the axis of the applied load, under the test block. They also record the average vertical settlement (bedding in) occurring during the test.

\section{Coefficient of friction}

The coefficient of friction is the ratio between the force parallel to the shear plane, and the force normal to the same.

The arrangement of the jack on the test block ensured that the applied load was parallel to the shear plane. However the applied load had a small (unavoidable) eccentricity above the shear plane resulting in an un-even distribution of bearing pressure, and hence some differential settlement of the test block occurred from time to time during testing. Also, whilst efforts were made to ensure that the 
test bed (bedding stone) was level, there was some small variation in bed slope due to its method of preparation and the way the block was initially sat on it.

The calculation of coefficient of friction $(\mu)$ was therefore corrected for the small bed slopes $(\alpha)$, less than 2 degrees, measured during the tests using the following relationship:

$$
\mu=\frac{(P+W \sin \alpha)}{W \cos \alpha} \text { where } \alpha \text { is small and can be +ve or -ve }
$$

\section{Test Programme}

In total 29 individual tests were carried out. 24 tests were carried out at $75 \mathrm{kPa}$ and 5 tests at $195 \mathrm{kPa}$ vertical effective stress. Testing was in three sets:

- Pre-production tests, based on a $180 t$ sample of the crushed granular bedding material

- Two sets of production tests based on the actual material properties of the crushed granular bedding material.

Each set included repeat testing. Testing at the higher (195kPa) vertical effective stress was only carried out during the initial pre-production testing.

\section{PRE-PRODUCTION TESTS}

Validation testing of the assumed coefficient of friction was a high priority and commenced early during the site establishment, and a pre-production sample (180 tonnes) of granular bedding material from the selected project quarry was provided for testing. During the design stage, angularity and shape of the granular bedding material had been assumed important, and although the material was nominally $100 \mathrm{~mm}$ single size, it was specified as a rock product with a weight grading - as this includes shape testing. This is shown converted to a size grading in Figure 6 below:

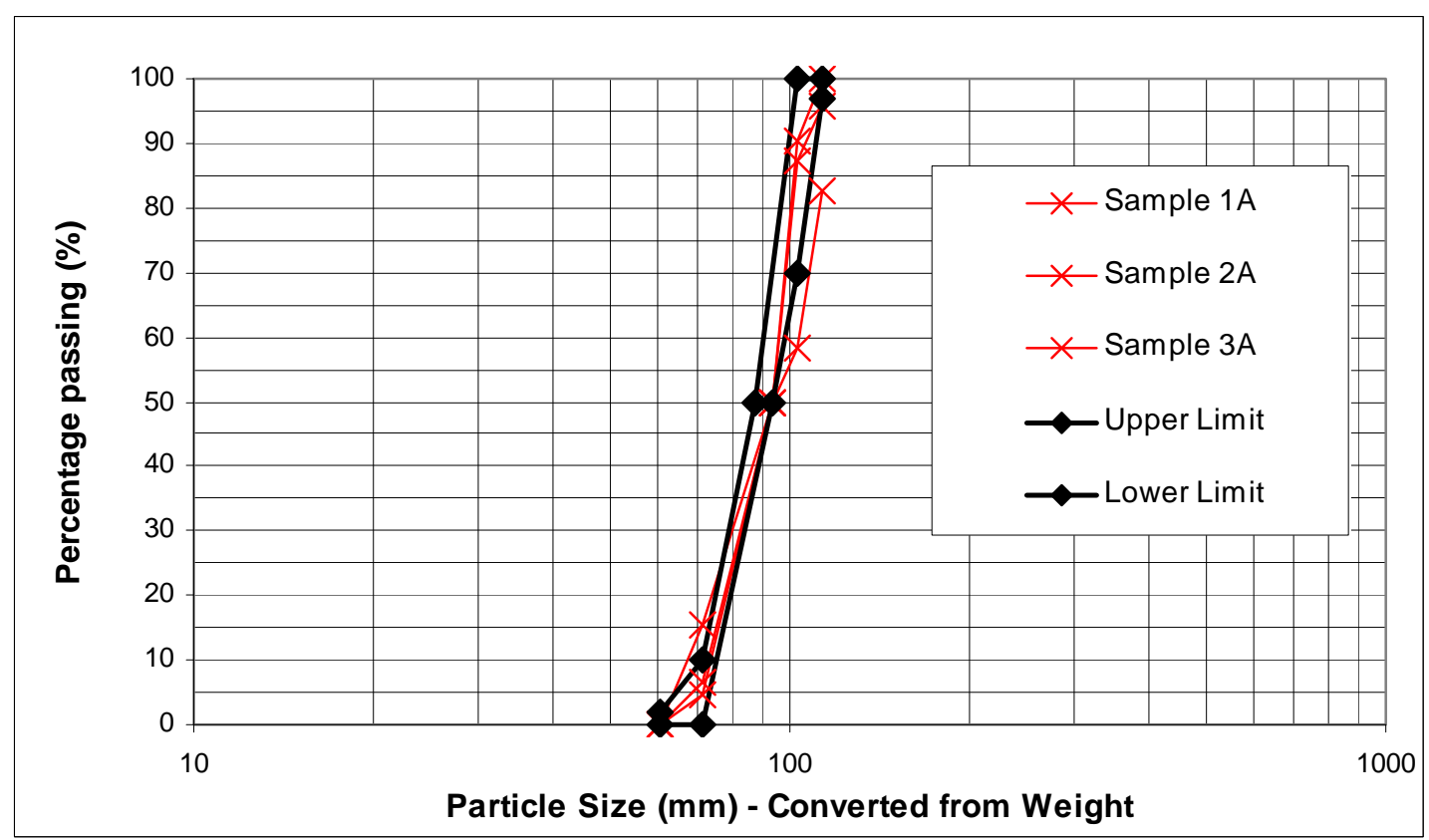

Figure 6 Particle Size Distribution - Pre-Production 100mm Single Size Granular Bedding Material

Whilst the sample provided met the grading requirements and, by virtue of being a crushed quarry material, the angularity, it did not comply with the specified shape requirement (44\% stones had $1 / \mathrm{d}$ $>3$ ). Testing continued with the provided sample without any further screening to improve shape. After each test the test bed was visually examined after lifting off the test block. On occasions slight point crushing of individual stones was noted, although typically no discernable degradation was seen [Figure 7]. The bedding material showed slight consolidation under the test block, and rearrangement of the top stones to take up the shape of the serrated base profile. 


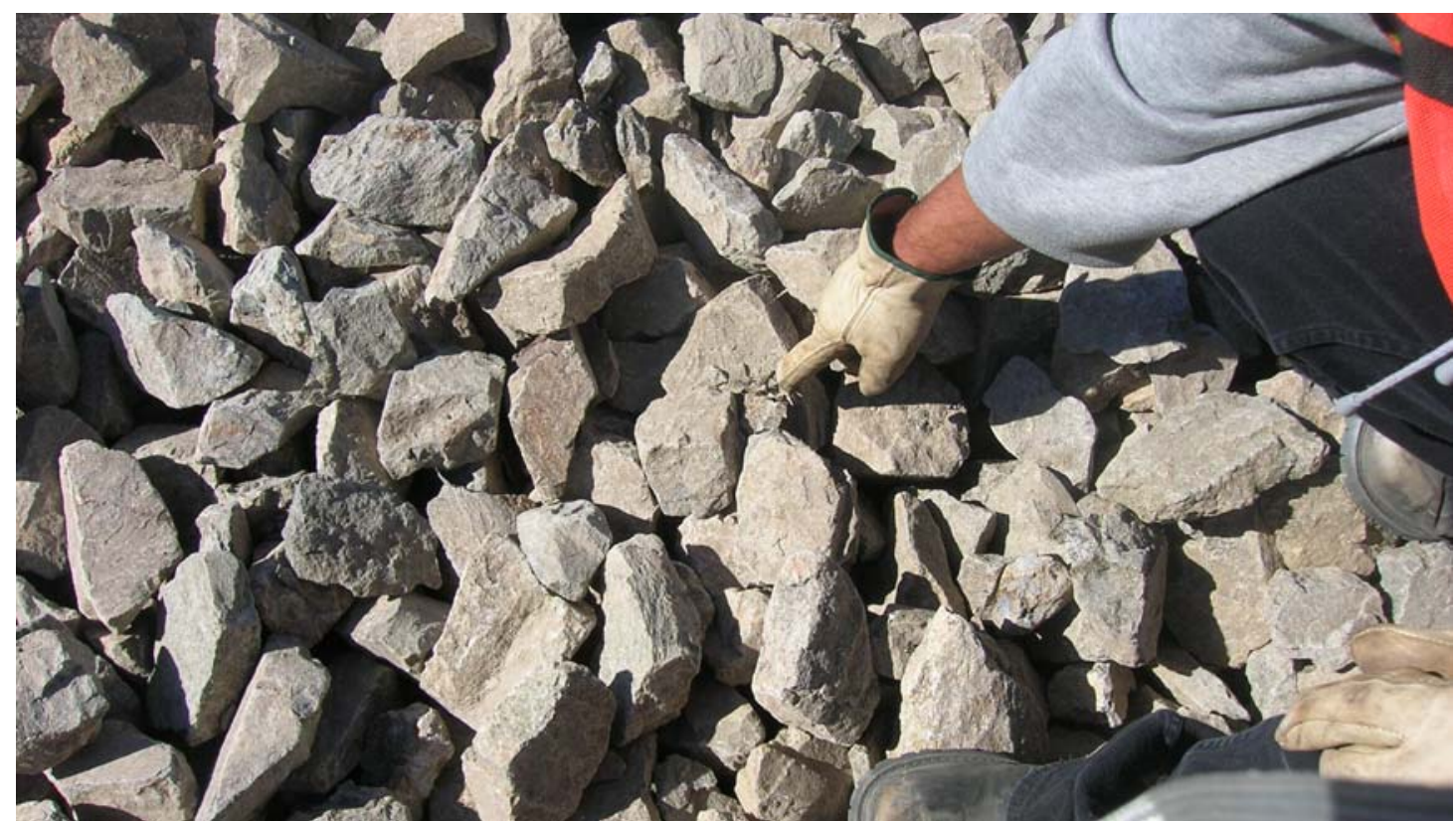

Figure 7 Visual Appearance - 100mm Single Size Granular Bedding Material (Post Test)

Test procedure was developed quickly during the initial test series. Prior to these the horizontal displacement had been uncertain. In particular it was found that bedding in occurred rapidly, and (high) rate of load application appeared to be unimportant. For tests at the higher bearing pressure it was better to add the kentledge after performing a test at the lower bearing pressure first. Some attempts to test at the higher bearing pressure from scratch on a loose bed resulted in uneven settlement and the test being abandoned.

\begin{tabular}{|c|c|c|c|c|c|c|c|}
\hline \multicolumn{3}{|c|}{ Tests at $75 \mathrm{kPa}$ Bearing Pressure } & \multicolumn{3}{|c|}{ Tests at $195 \mathrm{kPa}$ Bearing Pressure } & \multicolumn{2}{|c|}{ All Tests } \\
\hline Reference & $\delta H(\mathrm{~cm})$ & $\mu_{\lim }$ & Reference & $\delta H(\mathrm{~cm})$ & $\mu_{\lim }$ & $\delta H(\mathrm{~cm})$ & $\mu_{\lim }$ \\
\hline A2 01 & 12.8 & 0.790 & A2 08-195 & 43.8 & 0.829 & & \\
\hline A2 02 & 15.1 & 0.869 & A2 09-195 & 22.2 & 0.803 & & \\
\hline A2 03 & 14.5 & 0.939 & A2 10-195 & 21.6 & 0.774 & & \\
\hline A2 04 & 16.5 & 0.854 & A2 11 & 30.8 & 0.832 & & \\
\hline A2 05 & 19.6 & 0.781 & A2 12 & 20.7 & 0.811 & & \\
\hline A2 06 & 15.6 & 0.868 & & & & & \\
\hline A2 07 & 20.1 & 0.889 & & & & & \\
\hline A2 08-75 & 21.4 & 0.886 & & & & & \\
\hline A2 09-75 & 15.4 & 0.847 & & & & & \\
\hline A2 10-75 & 20.3 & 0.936 & & & & & \\
\hline Average & 17.1 & 0.866 & & 27.8 & 0.810 & 20.7 & 0.847 \\
\hline Standard Deviation & 2.96 & 0.052 & & 9.79 & 0.024 & 7.76 & 0.052 \\
\hline Coefficient of Variation & $17 \%$ & $6 \%$ & & $35 \%$ & $3 \%$ & $37 \%$ & $6 \%$ \\
\hline Probability $<$ & $90 \%$ & $10 \%$ & & $90 \%$ & $10 \%$ & $90 \%$ & $10 \%$ \\
\hline Characteristic Value & 20.9 & 0.799 & & 40.4 & 0.780 & 30.6 & 0.781 \\
\hline
\end{tabular}

During the pre-production testing [Table 4] three tests were carried out by performing a first test at $75 \mathrm{kPa}$ bearing pressure and then a second test at $195 \mathrm{kPa}$ without removing the test block and reconstructing the bedding layer. For one of these tests a delay of two days was made between the tests however there was no noticeable creep recovery before starting the second test. Limiting values for coefficient of friction $\left(\mu_{\mathrm{lim}}\right)$ and associated horizontal deflection $(\delta H)$ were found by fitting quadratic trend lines through the plotted test results. These are shown below in Figure 8. 


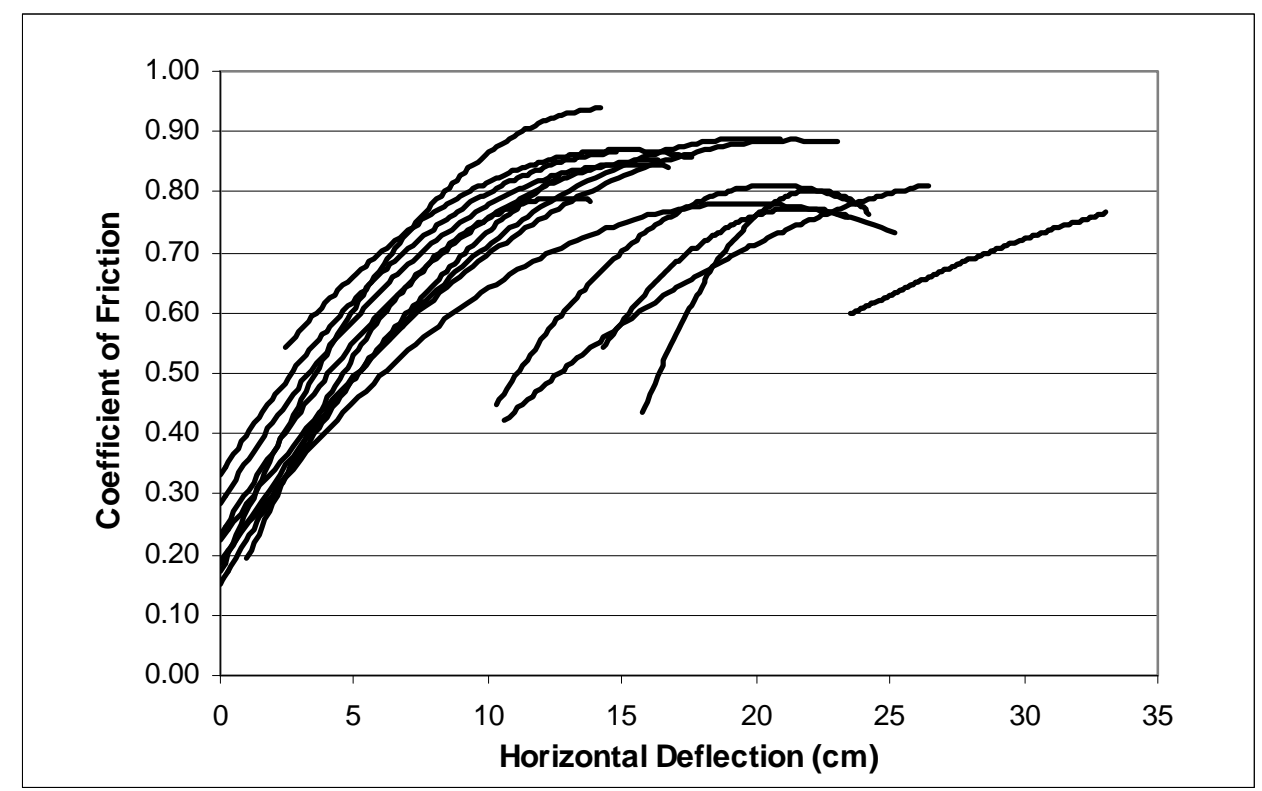

Figure 8 Summary Results - Quadratic trend lines Pre-Production Tests

Whist the pre-production sample was more tabular in shape than expected, the material performed in the tests as estimated in the design. In this knowledge, the bedding material was re-specified by size grading rather than weight grading, which is more readily understood for cobble sized material.

\section{PRODUCTION TESTS}

The project quarry was originally set up for commercial production of concrete aggregates, and up-scaling the pre-production sample of $100 \mathrm{~mm}$ granular bedding material was initially difficult. The nominal size of the material first supplied was smaller than specified $(70 \mathrm{~mm})$, and sampling showed a wider overall envelope [Figure 9]. The shape and angularity of this material was consistent with the pre-production test sample batch.



Figure 9 Particle Size Distribution - Initial Production 100mm Single Size Granular Bedding Material

Testing proceeded with the material as initially produced. Nine tests were carried out at $75 \mathrm{kPa}$ vertical effective stress [Table 5]. Average vertical settlement $(\delta V)$ was reported on in these tests: 


\begin{tabular}{|c|c|c|c|}
\hline \multicolumn{4}{|c|}{ Tests at $75 \mathrm{kPa}$ Bearing Pressure } \\
\hline Reference & $\delta V(\mathrm{~cm})$ & $\delta H(\mathrm{~cm})$ & $\mu_{\lim }$ \\
\hline B1 01 & 1.6 & 19.0 & 0.887 \\
\hline B1 02 & 1.4 & 14.8 & 0.727 \\
\hline B1 03 & 2.2 & 15.9 & 0.729 \\
\hline B1 04 & 0.7 & 12.8 & 0.818 \\
\hline B1 05 & 3.4 & 25.4 & 0.884 \\
\hline B1 06 & 2.5 & 18.1 & 0.879 \\
\hline B1 07 & 1.6 & 21.1 & 0.787 \\
\hline B1 08 & 2.5 & 27.8 & 0.849 \\
\hline B1 09 & 0.4 & 38.9 & 0.816 \\
\hline Average & 1.8 & 21.5 & 0.819 \\
\hline Standard Deviation & 0.96 & 8.12 & 0.062 \\
\hline Coefficient of Variation & $53 \%$ & $38 \%$ & $8 \%$ \\
\hline Probability $<$ & $90 \%$ & $90 \%$ & $10 \%$ \\
\hline Characteristic Value & 3.1 & 31.9 & 0.740 \\
\hline
\end{tabular}

These test results are consistent with the pre-production tests [Figure 10]. The presumption was made that testing with the higher vertical effective stress would follow the same trend as in the preproduction testing, and was not therefore carried out. The coefficient of friction is marginally reduced, which is assumed related to the slightly wider and smaller grading. The final caisson design was able to tolerate this small reduction in available sliding friction whilst maintaining adequate reliability against sliding during a design storm event.

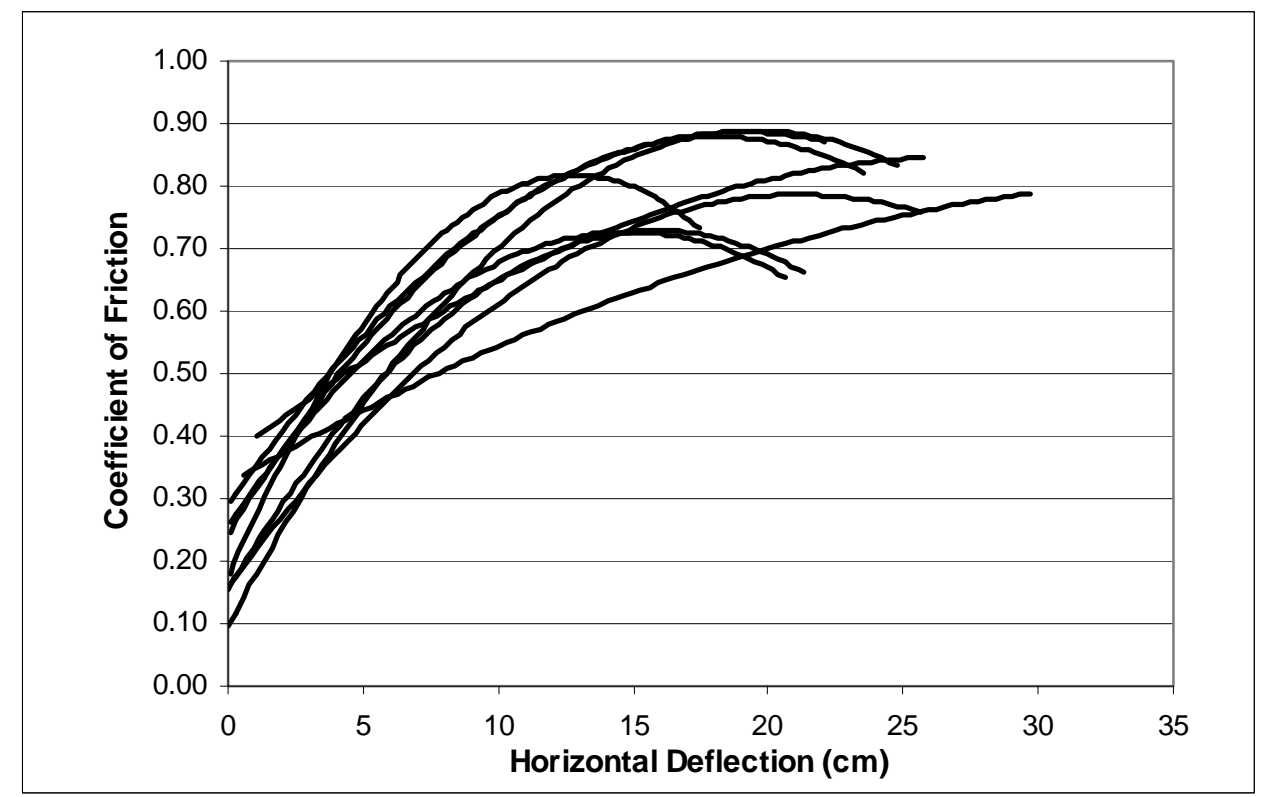

Figure 10 Summary Results - Quadratic trend lines Initial Production Tests

The initial production issues relating to settings in the secondary crusher and screen availability and selection at the quarry were overcome, and a more coarse single sized material was produced for the bulk of the granular bedding material. This material showed slight differences compared to the preproduction batch sample, and further testing was carried out to verify its performance in shear. Whilst the nominal size was correct, the grading [Figure 11] was slightly wider than in the pre-production sample. 


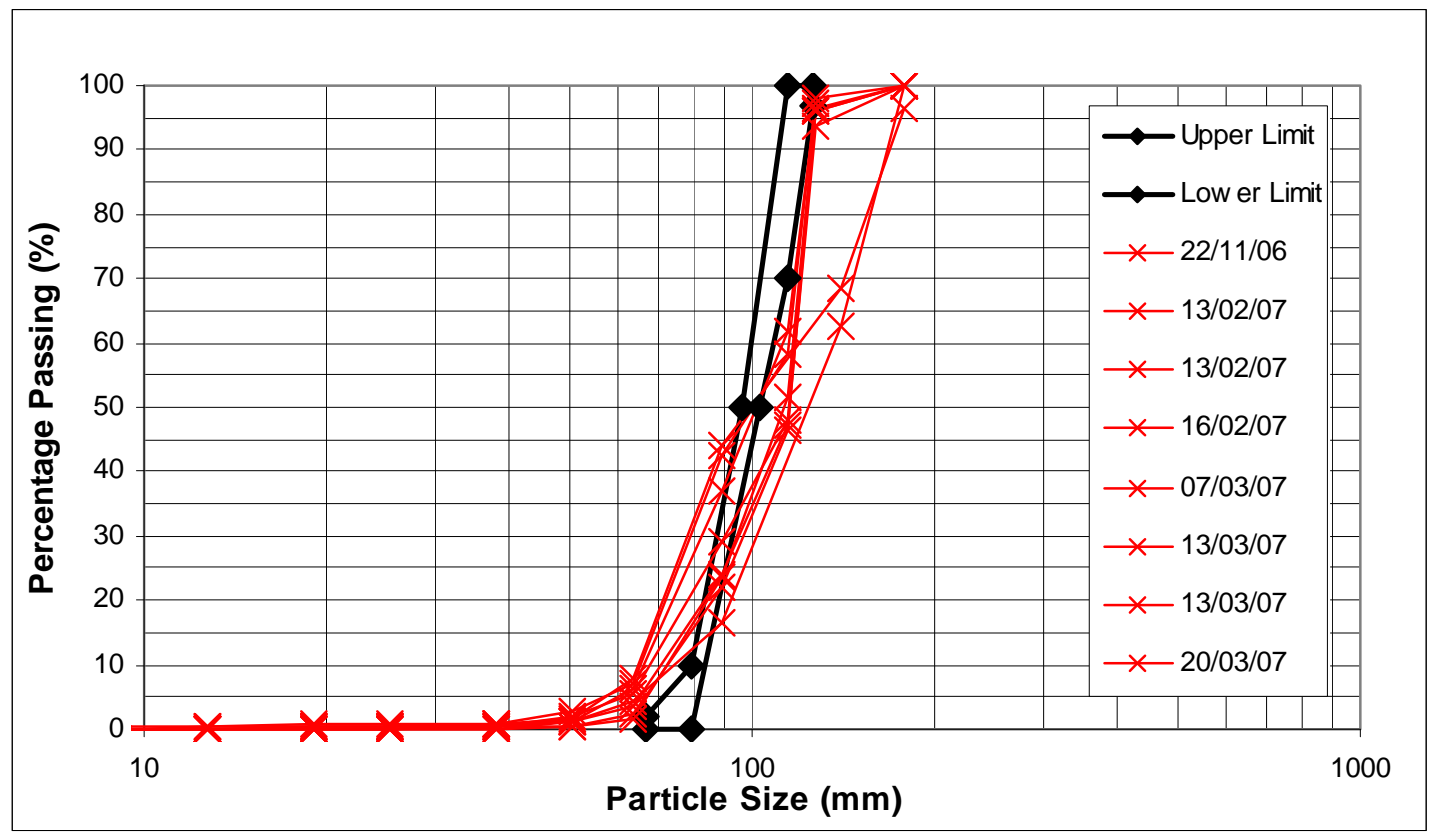

Figure 11 Particle Size Distribution - Production 100mm Single Size Granular Bedding Material

Five tests were carried out at $75 \mathrm{kPa}$ vertical effective stress:

\begin{tabular}{|c|c|c|}
\hline \multicolumn{3}{|c|}{ Table 6. Results Production Testing } \\
\hline \multicolumn{3}{|c|}{ Tests at $75 \mathrm{kPa}$ Bearing Pressure } \\
\hline Reference & $\delta H(\mathrm{~cm})$ & $\mu_{\lim }$ \\
\hline B2 01 & 11.2 & 0.828 \\
\hline B2 02 & 12.6 & 0.880 \\
\hline B2 03 & 16.6 & 0.873 \\
\hline B2 04 & 12.0 & 0.852 \\
\hline B2 05 & 15.7 & 0.859 \\
\hline Average & 13.6 & 0.858 \\
\hline Standard Deviation & 2.4 & 0.021 \\
\hline Coefficient of Variation & $17 \%$ & $2 \%$ \\
\hline $\begin{array}{l}\text { Applied Standard Deviation } \\
\text { (From Pre-Production Tests) }\end{array}$ & & 0.052 \\
\hline Probability $<$ & & $10 \%$ \\
\hline Characteristic Value & & 0.792 \\
\hline
\end{tabular}

The initial test results for this material [Table 6] confirmed that the assumed design value was achieved, and therefore this test series was curtailed early. The standard deviation and coefficient of variation for this short test series are less ( 0.021 and $2 \%$ respectively) than both the earlier test series, and therefore the characteristic value for coefficient of friction is estimated by assuming the standard deviation found in the pre-production testing.

\section{ANALYSIS \& DISCUSSION}

Whilst the original intention was simply to verify the coefficient of friction assumed in the design, the actual testing performed gave some insight into the following:

- $\quad$ Response under quasi-cyclic loading conditions

- Reliability

- Influence of particle shape, size and grading 
Response under quasi-cyclic loading

As explained earlier, the test arrangement required resetting of the hydraulic jack at frequent increments of horizontal deflection. Loading was intended to be static - ie not increased unless and until there was no further change in displacement. In terms of pile testing, achieving a static load condition can require significant time steps between load increments. However, during early testing it was found that the rate of load increase could be relatively fast [Figure 12]. In later testing the rate of loading used was deliberately unrestricted.

Whilst the test procedure could not replicate dynamic loading (period 16s) the cycle time to load and unload the hydraulic jack during the test was reduced to approximately 10 minutes after the initial load cycle to "bed in" the test, and hence may be considered as quasi-cyclic.

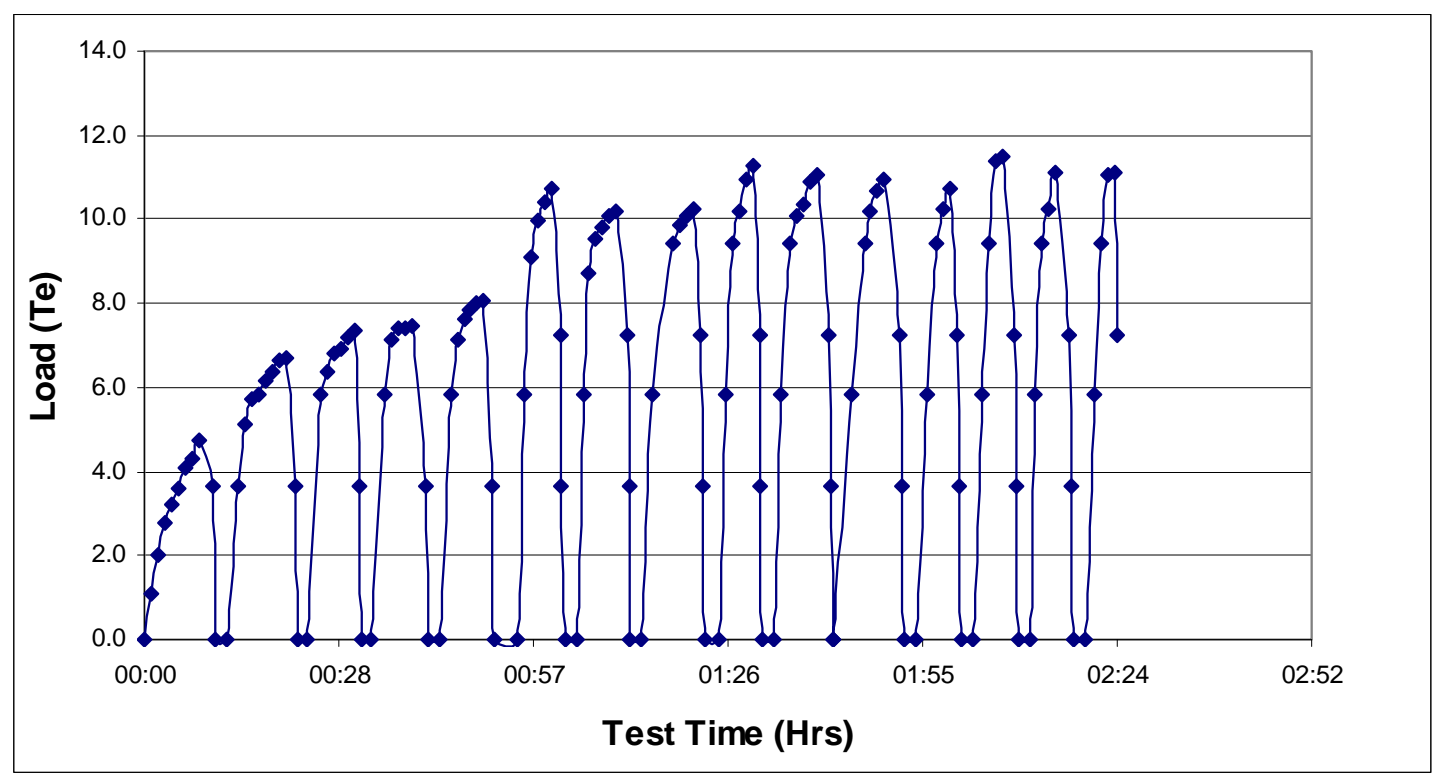

Figure 12 Typical Load vs Time plot for individual test [Reference B1 07]

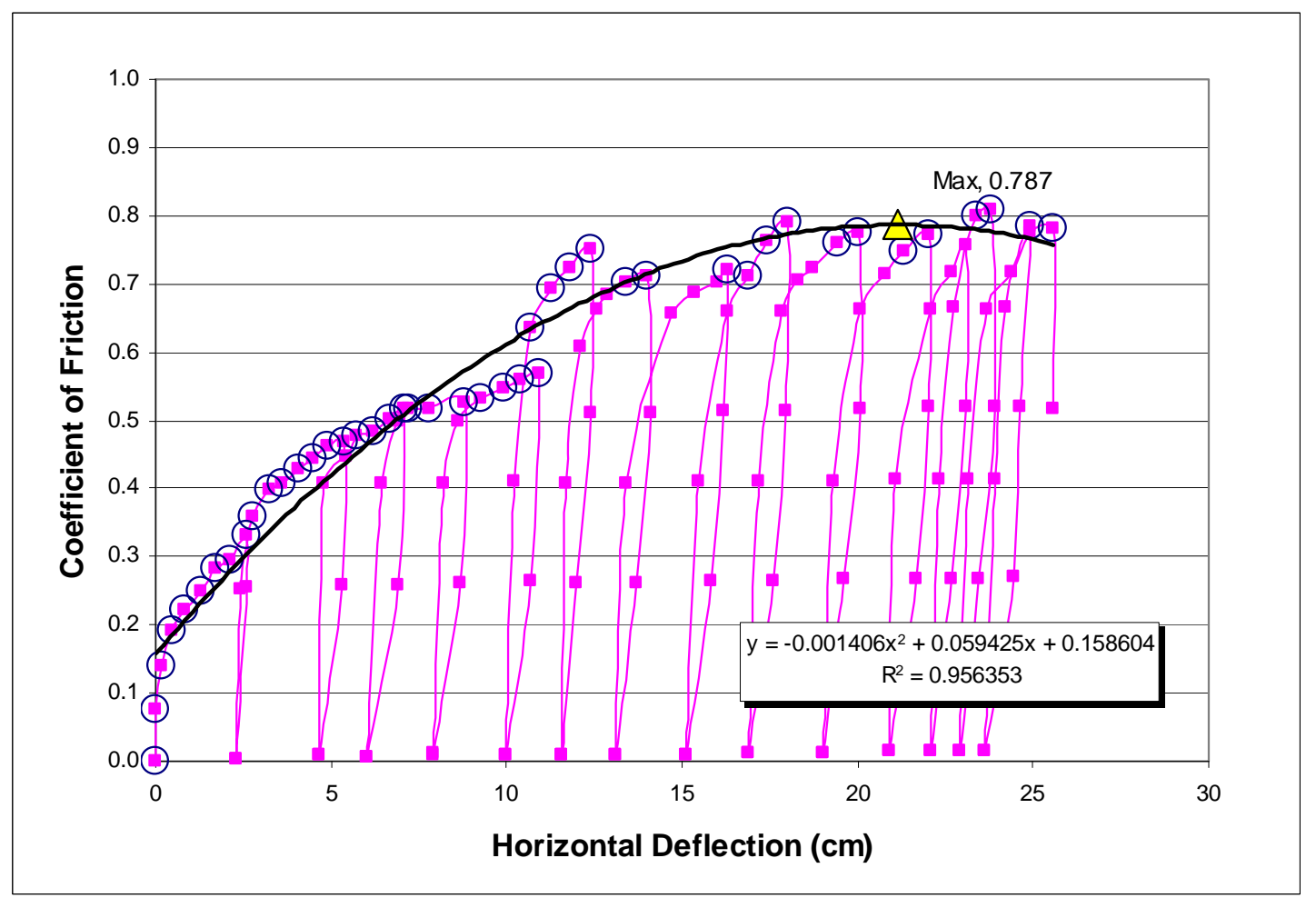

Figure 13 Typical Coefficient of Friction vs Horizontal Deflection plot for individual test [Reference B1 07] 
The above plot [Figure 13] show two distinct response curves for the horizontal shear of the concrete test block over the granular bedding material. Where applied loading exceeds that previously experienced, the increase in horizontal displacement is marked, and follows a virgin consolidation curve. During unloading and reloading the response is stiff and exhibits little elastic recovery. This dual response pattern is consistent with the consolidation and settlement response of soil to vertical loading and is not unexpected.

The important observation from this quasi-cyclic loading, up to the load required to generate limiting friction, is that horizontal displacement due to repeat loading is not cumulative.

\section{Limiting coefficient of friction $\left(\mu_{\text {lim }}\right)$}

Sliding resistance develops with increasing horizontal displacement up to a limiting value along the virgin consolidation curve. In order to find a limiting value from the test data, the following analysis steps were followed:

- filter out all data points that lie on the reload curves.

- fit a quadratic function, using the least squares method, through the remaining data points (on the virgin consolidation line).

- differentiate the fitted quadratic to determine the turning point of the function - giving a limiting value for coefficient of friction, and the associated horizontal displacement.

Each test was run until it was considered that a limiting value for the applied load had been reached. In most cases the limiting friction value was found within the test range, however in a few cases the test data is extrapolated to find the limiting friction. The values obtained by extrapolation are consistent with the other test results, and are not therefore discarded.

\section{Characteristic values}

The design is based upon a probability of failure within the structure lifetime (ULS Pf $=0.1$ ). The characteristic value of the coefficient of friction was found from statistical analysis of the test results with $10 \%$ probability of failure. Similarly, the characteristic value for associated horizontal displacement was found with $10 \%$ probability of exceedence.

\section{Influence of particle shape, size and grading}

The design made a conservative assumption about possible dilation (approx $10^{\circ}$ compared to a suggested value of $15^{\circ}$ ) in the granular bedding material, however the material produced (both the preproduction sample and production run) was more tabular (proportion with $1 / d>3$ ) than originally assumed. Sensitivity to this parameter was not tested.

Nominal particle size varied between the three test series, and some examination of trend can be made [Table 7]. For each test series the granular bedding material is characterized by its nominal size (D50) and its uniformity (D60/D10). The D50 is given as an average of the samples, and the upper D60/D10 is given (being D60max/D10min) for the envelope:

\begin{tabular}{|c|c|c|c|c|}
\hline \multicolumn{4}{|l|}{ Table 7. Trend - Coefficient of Friction } & \multicolumn{2}{l|}{ Coefficient of Friction } \\
\hline \multirow{3}{*}{ Test Series } & Granular Bedding Layer & $\begin{array}{c}\text { Expected value } \\
\text { (based on D50) }\end{array}$ \\
\cline { 2 - 5 } & $\begin{array}{c}\text { Nominal Particle } \\
\text { Size (D50) }\end{array}$ & $\begin{array}{l}\text { Envelope Uniformity } \\
\text { (D60/D10) }\end{array}$ & As tested & 0.78 \\
\hline A2 Pre-Production & $88 \mathrm{~mm}$ & 1.5 & 0.74 & 0.77 \\
B1 Initial Production & $76 \mathrm{~mm}$ & 5.3 & 0.79 & \\
B2 Production & $106 \mathrm{~mm}$ & 2.2 & & \\
\hline
\end{tabular}

It is reasonable that there is a small increase in coefficient of friction as D50 increases. It appears that with a wider grading (B1 test series) there is a small reduction in coefficient of friction.

\section{CONCLUSIONS}

The testing at prototype scale to verify the coefficient of friction assumed in the design confirmed that the use of a serrated profile over the full soffit of the caisson base slab permits the full angle of internal friction (after taking account of the angle of dilation) to be used for the angle of interface friction at the critical failure surface between the caisson base slab and the granular bedding layer.

This was verified for nominal $100 \mathrm{~mm}$ single size crushed granular bedding material, assumed to have an internal angle of friction of $45^{\circ}$ and an approximate dilation angle $10^{\circ}$, used under the offshore caisson breakwater installed at Costa Azul in 25m water depth to give a coefficient of friction 0.78 
(limiting value) with an associated horizontal displacement of $31 \mathrm{~cm}$. Derived characteristic design values are given with a $10 \%$ probability of failure/ exceedence.

Quasi-cyclic testing demonstrated that the response in shear follows a virgin consolidation curve, and that up to a limiting value unloading and reloading shows a much stiffer response with small elastic recovery. It is noted that repeat loading at less than the limiting value does not appear to have a cumulative creep effect.

By comparison of results from repeat testing in three test series it can be seen that there is a small increase in coefficient of friction with increase in nominal particle size for the granular bedding material. Increasing the width of the granular bedding material grading (uniformity) appears to result in a reduction in coefficient of friction.

\section{REFERENCES}

PIANC PTC II Working Group 28, Breakwaters with Vertical and Inclined Concrete Walls, Report, 2003

BS 6349 Part 2, Design of quay walls, jetties and dolphins, 1988

BS 6349 Part 7, Guide to the Design and Construction of Breakwaters, 1991

CIRIA Special Publication 83/ CUR Report 154, Manual on the use of rock in coastal and shoreline engineering, 1991 